\title{
Energy Star Lighting Verification Program (Program for the Evaluation and Analysis of Residential Lighting) Semi-annual report
}

For the period of April 2003 to October 2003

\author{
Authored by \\ Conan O'Rourke \\ and \\ Yutao Zhou \\ for \\ United States Department of Energy
}

March 2006

DOE Award Number DE-FG26-02NT41472

\author{
Lighting Research Center \\ Rensselaer Polytechnic Institute \\ 21 Union Street \\ Troy, NY 12180
}




\section{DISCLAIMER}

This report was prepared as an account of work sponsored by an agency of the United States Govemment. Neither the United States Govemment nor a ny of their employees, makes a ny wa ranty, express or implied, or assumes a ny legal liability or responsibility for the a c curacy, completeness, or usefulness of a ny information, apparatus, product, or process disc losed, or represents that its use would not infringe privately owned rights. Reference herein to any specific commercial product, process, or service by trade name, trademark, manufacturer, or otherwise does not necessa rily constitute or imply its endorsement, recommendation, or favoring by the United States Govemment or any agency thereof. The views and opinions of a uthors expressed herein do not necessa rily state or reflect those of the United States Govemment or any agency thereof.

No portion of this public ation or the information conta ined herein may be duplicated or excerpted in any way in other public ations, databases, or any other medium without express written permission from the PEARL Advisory Boa rd. It is against the law to present information extracted from this report for product publicity purposes.

The products described herein have not been tested for safety. The Lighting Research Center and Renssela er Polytechnic Institute make no representations whatsoever with regard to safety of products, in whatever form or combination used, and the results of the testing set forth for your information cannot be regarded as a representation that the products are or are not safe to use in any specific situation, or that the particularproduct you purchase will conform to the results found in this report.

The data in this report is a spot check of a partic ular model number from a partic ular manufacturer. The results cannot be regarded as a representation that all products with this model number will conform to the results. 


\begin{abstract}
The Program for the Evaluation and Analysis of Residential Lighting (PEARL) is a watchdog program. It was created in response to complaints received by utility program managers about the performance of certa in Energy Star lighting products being promoted within their service teritories and the lack of a selfpolic ing mechanism within the lighting industry that would ensure the reliability of these products and their compliance with ENERGY STAR specifications. To remedy these problems, PEARL purchases and tests products that a re available to the consumers in the marketplace. The Lighting Research Center (LRC) tests the selected products against the corresponding Energy Star specifications.

This report includes the experimental procedure and data results of Cycle Three and Cycle Four of PEARL program during the period of April 2003 to October 2003 , a long with the description of a pparatus used, equipment calibration process, experimental methodology, and research find ings from the testing. The parameter tested for $C y c$ le three is lumen maintenance at $40 \%$ rated life, and parameters tested for Cycle Four a re all parameters required in Energy Star specific ations exc ept lumen maintena nce at $40 \%$ ra ted life.
\end{abstract}




\section{TABLE OF CONIENTS}

DISCLAIMER

ABSTRACT 3

TABIE OF CONIENTS

USTOF GRAPHICALMATERIALS

INTRODUCTION 6

EXECUTIVE SUMMARY

$\begin{array}{ll}\text { EXPERIMENTAL } & 9\end{array}$

Apparatus $\quad 9$

Apparatus Calibration 9

Product Selection 9

Product Purchasing And Sampling 9

Product Testing 9

RESULTS AND DISCUSSION 10

CONCLUSION 10

REFERENCES

USTOF ACRONYMS AND ABBREVIATIONS 12

APPENDIX 1: APPARATUS 13

LRC LABORATORY DESCRIPTION

INTEG RATING SPHERE SYSTEM (ISS)

NATIONAL STANDARDS USED

SPEC TRAL/ FLUX CALBRATION OF THE ISS

Standard lamps used for calibration 14

Working standard lamp to be calibrated 15

Electrical equipment 15

Sphere Calibration Procedure 16

Calibration of the working standard 17

$\begin{array}{ll}\text { OTHER EQUIPMENT } & 17\end{array}$

REFERENCESFOR APPENDIX I 18

APPENDIX 2: RGURES $\quad 19$ 


\section{USTOF GRAPHICAL MATERIALS}

Figure 1. The integrating sphere system (ISS)

Figure 2. Measured line spectrum of the $\mathrm{HgCd} / 10$ spectral la mp

Figure 3. Relative spectral response of the ISS

Figure 4. Relative spectral response of the ISS with the spectral standard located inside the sphere 


\section{INTRODUCTION}

In response to numerous compla ints received by utility program managers about the performance of certa in ENERGY STAR ${ }^{\circledR}$ lighting products promoted within their service temitories, combined with the lack of industry-wide testing or selfpolicing mechanism, the Program for the Evaluation and Analysis of Residential Lighting (PEARL) was created. PEARL consists of utilities, energy effic iency advocates, and market transformation organizations. The Lighting Research Center (LRC) at Rensselaer Polytec hnic Institute in Troy, NY administers the program and performs the testing.

The ENERGY STAR labeling program for residential lighting products merely requires data submission and certific ation by the product manufacturers. Product samplestested a re "self-picked" by the manufacturer. No follow-up testing on actual products purchased from retail is required by ENERG Y STAR. In addition, no centra lized data review or challenge process exists within the lighting industry relative to the performance of residential ENERGY STAR lighting products.

This report conta ins the experimental procedure and research findings for the testing of Energy Star products in Cycle Three and Cycle Four of PEARL program during the period of April 2003 to October 2003. 


\section{EXECUTIVE SUMMARY}

PEARL is a watchdog program created to monitor the performance of certain Energy Star lighting products being promoted by utility companies. PEARL purchases and tests products that is available to the consumers in the marketplace.

During the period of to April 2003 to October 2003, LRC performed testing for two cycles of PEARL program --- Cycle Three and Cycle Four. For Cycle three, lumen ma intenance at $40 \%$ rated life was tested for CFLs. For Cycle Four, all pa rameters required in Energy Star specific ations were tested or evaluated, except lumen ma intenance at $40 \%$ rated life. This report includes the experimental process and data results of the performed testing and description of apparatus used, equipment calibration process, experimental methodology, and research findings from the experiment.

For Cycle Three, all CFLs were sea soned to $40 \%$ rated life first. Some CFL samples failed before reaching $40 \%$ rated life and some were excluded from results a na lysis for va rious rea sons: Two 3-wa y models were tested at middle wattage instead of highest wattage as stated in the Energy Star specifications, and one model was de-listed by Energy Star between the time it was selected and the time when testing was completed. For the remaining 80 samples at the end of their $40 \%$ rated lives, 45 CFL samples failed to meet the requirement of lumen maintenance at $40 \%$ rated life. Almost all covered lamp and reflector lamp samples failed this requirement.

For Cycle Four, the PEARL board selected 20 product models of compact fluorescent lamps (CFLS) and nine product models of fixtures to test. The $20 \mathrm{CFL}$ models include different types of sc rew-ba sed CFLs such as ba re la mp, covered lamp, reflector lamp, and 3-way lamps, ranging from nine to 30 watts in rated power. These CFLs were made or marketed by 11 different manufacturers. The nine fixture models include eight indoor fixtures and one outdoor fixtures. The ind oor fixtures include different types such as wall-mounted, ceiling mounted, and portable fixtures. Products were selected based on their availability in the consumer retail market. The CFL product samples were purchased from retail stores and shipped to the LRC for testing. The fixtures were purchased by LRC from local retailers. Sponsors were divided into three regions for procuring the products: Northeast/Midwest, Northwest, and Ca lifomia.

For CFLs in Cycle Four, the parameters tested include Efficacy, 1000-hour lumen ma intenance, Rapid Cycle Stress Test, Power Factor (PF), Correlated Color Temperature (CCT), Color Rendering Index (CRI), and run-up time, etc. For fixtures, the parameters tested include System Efficacy, Lamp Start Time, PF, CCT, $\mathrm{CRI}$, etc. Besides, a series of parameters were verified such as input voltage and frequency, lamp base, starting temperature, compatibility with controls, wa rra nty, Energy Star label, Labeling (including incandescent equivalence), and a verage rated lamp life for CFLs, and fixture warranty, safety information, Energy Star label, lamp life, noise level, and ballast information for fixtures. 
One of the $20 \mathrm{CFL}$ models was removed from the results a nalysis due to the following reason: Samples received for this CFL model were actually two different models, even though the manufacturer claimed they were the same. For the remaining 19 models of CFL, $5 \%$ fa iled to meet Effic a cy requirement, $37 \%$ failed to meet 1000 -hour lumen maintenance requirement, and $28 \%$ failed Rapid Cycle Stress Test requirement. All eight indoor fixtures met System Efficacy requirement, and two failed to meet Lamp Start Time requirement. Socket Compatibility for the outdoor fixture is questionable.

Other than the parameters included in Energy Star specifications, LRC also made observations on other quality problems related to the selected products, and made recommendations on possible modific ations to Energy Star specific ations. 


\section{EXPERIMENTAL}

\section{Apparatus}

Please refer to Appendix I of this doc ument for desc ription of apparatus used for testing in PEARL program.

\section{Apparatus Calibration}

LRC integrating sphere system wascalibrated when necessary. Three calibrations were performed in the period of April 2003 to October 2003, in J une, J uly, and September 2003.

Other equipment, including the Xitron 2503AH Power a na lyzer and Agilent 34970A Data Acquisition Unit, was calibrated annually.

\section{Product Selection}

The PEARL board selected 20 product models of compact fluorescent la mps (CFLs) and nine product models of fixtures to test. Products were selected based on their a va ila bility in the consumer reta il ma rket. Initia lly, PEARL sponsors went to retail stores to see what products were available. Then, the products from the compiled list were purchased and shipped to the LRC for testing.

\section{Product Purchasing and Sampling}

For details on product purchasing and sampling, plea se refer to PEARL Cycle Three Final Report and PEARL Cyc le Four Final Report.

\section{Product Testing}

PEARL tested the CFL products a ga inst the ENERGY STAR specification dated August 9, 2001, and tested the fixture products aga inst the ENERGY STAR specific ation Version 3.1 that was effective on April 1, 2002. All CFL and fixture testing was performed at the LRC. Product verific ation and compilation of results were also completed by the LRC.

For details on testing parameters and test methods plea se refer to PEARL Cycle Three Final Report and PEARL Cycle Four Final Report. 


\section{RESULTS AND DISC USSION}

The testing results of all CFLs and fixtures are presented in PEARL Cycle Three Final Report and PEARL Cycle Four Final Report, a long with disc ussions of other quality problems that $L R C$ found about the products during the testing and some recommendations on possible mod ific ations to Energy Star spec ific ations. For more details please refer to PEARL Cycle Three Final Report and PEARL Cycle Four Final Report.

\section{CONCLUSION}

In Cycle Three, 56\% CFL models failed to meet the requirement of lumen maintenance at $40 \%$ rated life, and a lmost all covered la mps and reflector lamps failed this requirement.

In Cycle Four, $95 \%$ of the CFL models tested meet the Effic ac y requirement, $72 \%$ met Rapid Cycle Stress Test requirement, and 63\% met 1000-hour lumen ma intenance requirement. All eight indoor fixtures met System Effic acy requirement and two failed to meet Lamp Start Time requirement.

In Cycle Four, covered lamps and reflector lamps have a lower rate of meeting the 1000-hour lumen ma intenance requirement. This a grees with our finding from PEARL C ycle Three --- covered lamps and reflector lamps tend to be problematic, probably due to the raised ambient temperature for the fluorescent tube inside the housing of the cover or reflector. This conclusion a Iso agrees with the research findings from LRC in the past --- extra heat affects fluorescent lamps' performance adversely.

As shown in previous cycles of PEARL program, products from different manufacturers continue to perform differently, and there is one model from a certa in ma nufacturer that had all five samples failed before reaching $40 \%$ of rated life.

Other qua lity problems exist besides the Energy Star specified parameters, such as reflector glass cracking under heat and inconsistent claims and packaging for different samples of the same model. 


\section{REFERENCES}

Energy Star, “Energy Star Program Requirements for CFLs", Version 8/9/01.

Energy Star, "Energy Star Program Requirements for Resid ential Lighting Fixtures", Version 3.1.

O'Rourke, C. and Zhou, Y., "Program for the Evaluation and Analysis of

Residential Lighting Final Report: Testing Cycle Three", May 2003

O'Rourke, C. and Zhou, Y. , "Program for the Evaluation and Analysis of Residential Lighting Final Report: Testing Cycle Four", December 2003

RAND, “A Million Random Digits with 100,000 Nomal Deviates", Published 2001 by RAND

ANSI C 62.41:1991 IEEE Recommended Practice for Surge Volta ges in LowVoltage AC Power Circ uits

ANSI C 78.4:1998 American National Standard for Fluorescent Lamps - SelfSupporting, Single-Based, Compact Types-Dimensional and Electric al Characteristics

ANSI C 78.5:1997 American National Standard for Elec tric al Lamps - Specific ations for Performance of Self-Ba llasted Compact Fluorescent Lamps

ANSI C 82.3:1995 Americ an National Standa rd Specific a tions for Fluoresc ent Lamp Reference Ballasts

IES LM-20:1994 Photometric Testing of Reflector-Type Lamps

IES LM-40: 2001 Life Performance Testing of Fluorescent La mps

IES LM-45:2000 Elec tric al and Photometric Mea surements of G eneral Service Inc andesc ent Fila ment Lamps

IES LM-49:2001 Life Testing of General Lighting Inc andesc ent Fila ment La mps

IES LM-54:1999 IES Guide to Lamp Seasoning

IES LM-58:1994 Spectroradiometric Measurements

IES LM-65:2001 Life Testing of Single Ended Compact Fluorescent La mps IES LM-66:2000 Elec tric al and Photometric Mea surements of Single-Ended Compact Fluorescent Lamps

IES LM-9:1999 Elec tric al and Photometric Measurements of Fluorescent Lamps

NIST HB 150-1:1994 National Voluntary Laboratory Accreditation Program (NVLAP) Handbook for Energy Efficient Lighting Products. Lawrence S. Galowin, Wiley Hall, and Walter J . Rossiter, J r.

NBST PB93 196038 Experimental Statistic s Hand book 1991

UL 1993 Standard for Sa fety for Self-Ballasted Lamps and Lamp Adapters 


\section{USTOF ACRONYMS AND ABBREVIATIONS}

$\begin{array}{ll}\text { AC } & \text { Altemative Current } \\ \text { ANSI } & \text { American National Standard Institute } \\ \text { CCF } & \text { Current Crest Factor } \\ \text { CCT } & \text { Correlated Color Temperature } \\ \text { CFL } & \text { Compact Fluorescent Lamp } \\ \text { CRI } & \text { Color Rendering Index } \\ \text { DC } & \text { Direct Current } \\ \text { IES } & \text { Illuminating Engineering Society } \\ \text { ISS } & \text { Integrating Sphere System } \\ \text { Lm } & \text { Lumen } \\ \text { IES-LM } & \text { Illuminating Engineering Society Lighting Mea surement Guidance } \\ \text { LRC } & \text { Lighting Research Center } \\ \text { NEMA } & \text { National Electrical Manufacturers Association } \\ \text { NLPIP } & \text { National Lighting Product Information Program } \\ \text { PEARL } & \text { Program for the Evaluation and Analysis of Residential Lighting } \\ \text { PF } & \text { Power Factor } \\ \text { RPI } & \text { Rensselaer Polytechnic Institute } \\ \text { UL } & \text { Underwriter Laboratories } \\ \text { W } & \text { Watt }\end{array}$




\section{APPENDIX 1: Apparatus}

\section{LRC Laboratory Description}

The Lighting Research Center (LRC), part of Rensselaer Polytec hnic Institute, is a university-based research and education institution dedic ated to lighting. Its laboratory performs testing of energy effic ient products for the Program for the Evaluation and Analysis of Residential Lighting (PEARL), the National Lighting Product Information Program (NLPIP), and some research for the LRC's partners.

Located at 21 Union Street in Troy, New York, the LRC laboratory employs a staff of 12 (plea se see the organizational chart). The lab consists of three sub a reas, of a total size of 2060 square feet: the 20x8 foot Balla st Testing Room, the 34x30 fo ot Lamp Testing Room, and the $44 \times 20$ foot Photometry Lab.

\section{Integrating Sphere System (ISS)}

The main apparatus in Lamp Testing Room is an Integrating Sphere System (ISS). The ISS c onsists of following items/instruments:

- Integrating sphere; interior access type, 65-inch dia meter (Mfg: Labsphere, Model: IAS650) Figure 1

- Double monochromator at $5 \mathrm{~nm}$ band pass (Mfg: Optronic Laboratories, Model: 750-M-D)

- Entrance slit width $-1.25 \mathrm{~mm}$

- Exit slit width $-1.25 \mathrm{~mm}$

- Center slit width $-2.5 \mathrm{~mm}$

- Enhanced silic one detector module (Mfg: Optronic Laboratories, Model: DH300)

- Detector support module (Mfg: Optronic Laboratories, Model: DSM-1D)

- System controller for the monoc hromator/ detec tor system (Mfg: Optronic Laboratories, Model: 750-C)

- OL750 application software (supplied by Optronic Laboratories)

- Personal computer with Windows NT4.0 (Mfg: Dell, Model: OptiPlex GX1p)

- GPIB Interface (Mfg: National Instruments, Model: GPIB-PCI)

\section{National Standards Used}

The national standards used in the testing for LRC testing lab a re from ANSI/NEMA, UL, and Illuminating Eng ineering Society (IES). Below is a list of them:

- ANSI C62.41:1991 IEEE Recommended Practice for Surge Voltages in Low-Voltage AC Power Circuits

- ANSI C 78.4:1998 American National Standard for Fluorescent LampsSelf-Supporting, Single-Based, Compact Types - Dimensional and Elec tric al Cha rac teristic s

- ANSI C 78.5:1997 American National Standard for Electrical LampsSpec ific a tions for Performance of Self-Ba lla sted Compact Fluorescent Lamps 
- ANSI C82.3:1995 Americ an National Standard Specific ations for Fluorescent Lamp Reference Ballasts

- IES LM-20:1994 Photometric Testing of Reflector-Type Lamps

- IES LM-40: 2001 Life Performance Testing of Fluo resc ent La mps

- IES LM-45:2000 Electrical and Photometric Mea surements of General Service Inc andescent Fila ment Lamps

- IES LM-49:2001 Life Testing of General Lighting Inc a ndescent Fila ment Lamps

- IES LM-54:1999 IESG uide to Lamp Seasoning

- IES LM-58:1994 Spectroradiometric Measurements

- IES LM-65:2001 Life Testing of Single Ended Compact Fluorescent Lamps

- IES LM-66:2000 Electrical and Photometric Measurements of SingleEnded Compact Fluorescent Lamps

- IES LM-9:1999 Electric al and Photometric Measurements of Fluorescent Lamps

- NIST HB 150-1:1994 National Voluntary Laboratory Acc reditation Program (NVLAP) Handbook for Energy Effic ient Lighting Products. Lawrence S. Galowin, Wiley Hall, and Wa Iter J. Rossiter, J r.

- NBSTPB93 196038 Experimental Statistic s Handbook 1991

- UL 1993 Standard for Safety for Self-Ballasted Lampsand Lamp Adapters

\section{Spectral/flux Ca libration of the ISS}

The calibration procedure enables the integrating sphere system (ISS) to measure photometric output of test lamps. The process involves the determination of the relative spectral response of the ISS and nomalization of the photometric output to a known flux standard(s). The rela tive spectral response is determined by comparing a spectral iradiance standard with the system response to the standard. This is done over the desired range of wavelengths. Once the relative spectral response is determined the flux standard(s) is used to nomalize the system output to the known photometric output of the standard.

\section{Standard lamps used for calibration}

The following spectral/flux standards were used in the calibration process. All standards a re traceable to NIST.

\section{Relative spectral iradiance standard}

FEL type incand escent la mp, traceable to NIST (Mfg: Hoffman Engineening, SN: 94406)

- Lamp current:

$7.204 \mathrm{~A}(\mathrm{DC})$

- Lamp voltage: $84.5 \mathrm{~V}(\mathrm{DC})$

- Correlated color temperature: $2856 \mathrm{~K}$

- CIEX: 0.448

- CIEy:

0.408

- Spectral range:

350 to $1100 \mathrm{~nm}$ 
Flux standards, 200W Wi40/G lobe inc andescent, inside frosted, calibrated at NIST (Mfg: Osram)

$$
\begin{aligned}
& \text { Lamp_RPI_1 } \\
& \text { - Lamp current: } \\
& 5.725 \mathrm{~A} \\
& \text { - Lamp voltage: } \\
& 29.36 \mathrm{~V}
\end{aligned}
$$

Lamp_RPI_2

- Lamp current:

$5.728 \mathrm{~A}$

- Lamp voltage:

$29.45 \mathrm{~V}$

- Luminous flux:

2288 lumens

- Correlated color temperature:2750 K

$$
\text { Lamp_RPI_3 }
$$

- Lamp current:

- Lamp voltage:

- Luminous flux:

2234 lumens

- Correlated color temperature:2750 K

Spectral lamp (Mfg: Osram)

- Lamp type:

$\mathrm{HgCd} / 10$

\section{Working standard lamp to be calibrated}

The following lamp was calibrated for luminous flux using the calibrated ISS.

Lamp RPI_WS, 200W incandescent, clear (Mfg: Osram)

- Type: Wi 40/G

- Rated voltage: $\quad 31.0 \mathrm{~V}$

- Rated current: $\quad 6.0 \mathrm{~A}$

\section{Electrical equipment}

- DC power supply (Mfg: Hewlett Packard, Model: 6675A)

- AC power supply (for the $\mathrm{HgCd} / 10$ spectral la mp; Mfg: Gates, Model: 12S-9)

- Data acquisition/switch unit (Mfg: Agilent Technologies, Model: 34970A)

- 20-channel multiplexer (Mfg: Agilent Tec hnologies, Model: 34901A)

- Bench type multimeter (Mfg: Hewlett Packard, Model: 34401A)

- Shunt resistance (Mfg: Isotek, Model: RUG-R050, $50 \mathrm{~m} \Omega$ )

- Computer controlled data a cquisition system (using GPIB) 


\section{Sphere Calibration Procedure}

The whole calibration process involves three steps:

- Wavelength calibration

- Relative spectral response calibration

- Flux calibration

Wavelength calibration

The monochromator system is pre-calibrated for wavelength. The experimental procedure was to detemine possible changes in the pre-calibration due to shipping/handling etc.

The spectral $(\mathrm{HgCd} / 10)$ lamp was mounted at the center of the sphere. It was tumed on and stabilized for about 20 minutes before the test. A spectral scan from 360 to $650 \mathrm{~nm}$ at $0.2 \mathrm{~nm}$ intervals was taken using the monochromator system. Known spectral peaks for $\mathrm{Hg}$ and $\mathrm{Cd}$ were compared aga inst the measured peaks. See Figure 2.

\section{Relative Spectral Response Calibration}

The relative spectral response of the ISS was detemined using the spectral iradiance standard lamp 94406. The spectral data for the lamp were imported to the software program (software supplied by Optronic Laboratories).

The DC power supply was used to power up the lamp. The current limit was set at 7.204 A, and the power supply was operated at the constant current (CC) mode. The DC voltage across the shunt was monitored using the Data acquisition/switch unit to ma intain the la mp current. The lamp voltage was measured using the multimeter. Lamp was stabilized for about 15 minutes before the scan. The room temperature was recorded at regular intervals.

A spectral scan from 350 to $800 \mathrm{~nm}$ was taken using the double monochromator system. The relative spectral response of the system is the ratio of the standard spectral data of the lamp to that of scanned data (the software program does the math automatic ally) for the wavelength range from 350 to $1100 \mathrm{~nm}$. Figure 4 illustrates the system spectral response calibration curve.

Even though there was a slight disc repancy (figure 3) in the measured spectral power distribution of the spectral standard (94406) a round $600 \mathrm{~nm}$ region, it produced close results of the reported CCTand chromatic ity coordinates. Therefore the error introduced by placing the lamp inside the sphere is assumed negligible.

\section{Fluxcalibration}

The flux calibration was done using two flux standards RPI_2 and RPI_3 (calibrated at NIST). The lamp (RPI_2) was mounted at the center of the sphere. The DC power supply was used to power up the lamp. Current was set at 5.728 
A, and the power supply was run at the CC mode. Lamp was stabilized for about 15 minutes before the test. The lamp current was monitored using the Data acquisition/switch unit to maintain the la mp current. The lamp voltage was measured using the multimeter. The room temperature was recorded at regular intervals.

A spectral scan from 350 to $1100 \mathrm{~nm}$ wastaken using the double monochromator system. The same procedure was repeated for the lamp RPI_3. Photometric calculations were performed using the software program. The photometric output for each lamp was used to obtain the normalization factor to find the absolute luminous flux.

The flux standard RPI_1 wastested using the calibrated ISS to check the calibration. The lamp wasoperated using the same DC power supply similar to the manner described above for RPI_2 and RPI_3 at the specified current of 5.725 A.

\section{Calibration of the working standard}

The working standard was calibrated using the calibrated ISS. The lamp (working standard) was mounted at the center of the sphere. The DC power supply was used to power up the lamp. Current was set at $5.728 \mathrm{~A}$, and the power supply was run at the CC mode. Lamp wasstabilized for about 15 minutes before the test. Stabilization was determined by monitoring the la mp current. When the lamp current changes less than $0.01 \%$ within 3 minutes, the lamp is considered as stable in its current and its light output. The lamp current was monitored using the Data acquisition/switch unit to mainta in the lamp current. The lamp voltage (29.468 V, at the lamp leadsabout 6 inches a way from the actual lamp teminals) was measured using the multimeter. The room temperature was recorded at regular intervals.

A spectral scan from 350 to $800 \mathrm{~nm}$ was taken using the double monochromator system. Photometric calculations were performed using the software program.

The a uxiliary lamp ( $12 \mathrm{~V}$, Quartz halogen) was used to determine the selfabsorption factor for flux standards. The DC power supply was used to power up the lamp. Current was set at $2.869 \mathrm{~A}$, and the power supply was run at the CC mode. Lamp was stabilized about 10 minutes before the test. Two spectral scans from 380 to $800 \mathrm{~nm}$ were taken with and witho ut the unlit flux standard RPI_1 inside the sphere. The software program was used to determine the numerical sum of each scan, and the ratio was used as the self-absorption factor.

\section{Other Equipment}

- Lamp Racks

- Fixture Racks

- Double Monochromator and Controller 
- Instrument Rack:

- Power meter

- Data acquisition unit

- Multimeter

- Pic oammeter

- AC Power Supply

- DC Power Supply

- Examination Tables

- Computers

\section{Referencesfor Appendix I}

ISO 1993. Guide to the Expression of Uncerta inty in Measurement. Intemational Organization for Standardization, Switzerland 1993.

Gamer J.L. 2000 (2000 Oct. J oumal, yet to publish)

Kostkowski H.J . 1997. Reliable Spec troradiometry. Spec trora diometry Consulting, Maryland, 1997.

NBS Tec hnic al Note 910-1. Self Study manual on Optic al Radiation Mea surements - Part 1 - Concepts, Chapters 1 to 3. U.S. Department of Commerce/National Bureau of Standards. 1976.

NBS Tec hnic al Note 910-2. Self Study manual on Optic al Radiation Mea surements - Part 1 - Concepts, Chapters 4 to 5. U.S. Department of Commerce/National Bureau of Standards. 1978.

Ohno Y. and Daubach O. 2000. Integrating Sphere Simulation on Spatial Nonunifo mity Errors in Luminous Flux Measurement. IESNA Annual Conference, Wa shington DC, J ul. 31 - Aug. 2, 2000.

Short Course on Photometry, September 14-17, 1999. Section 11, Handouts and Reference Materia Is. National Institute of Standards and Technology, Optical Technology Division, Gaithersburg, MD. 


\section{APPENDIX 2: Figures}

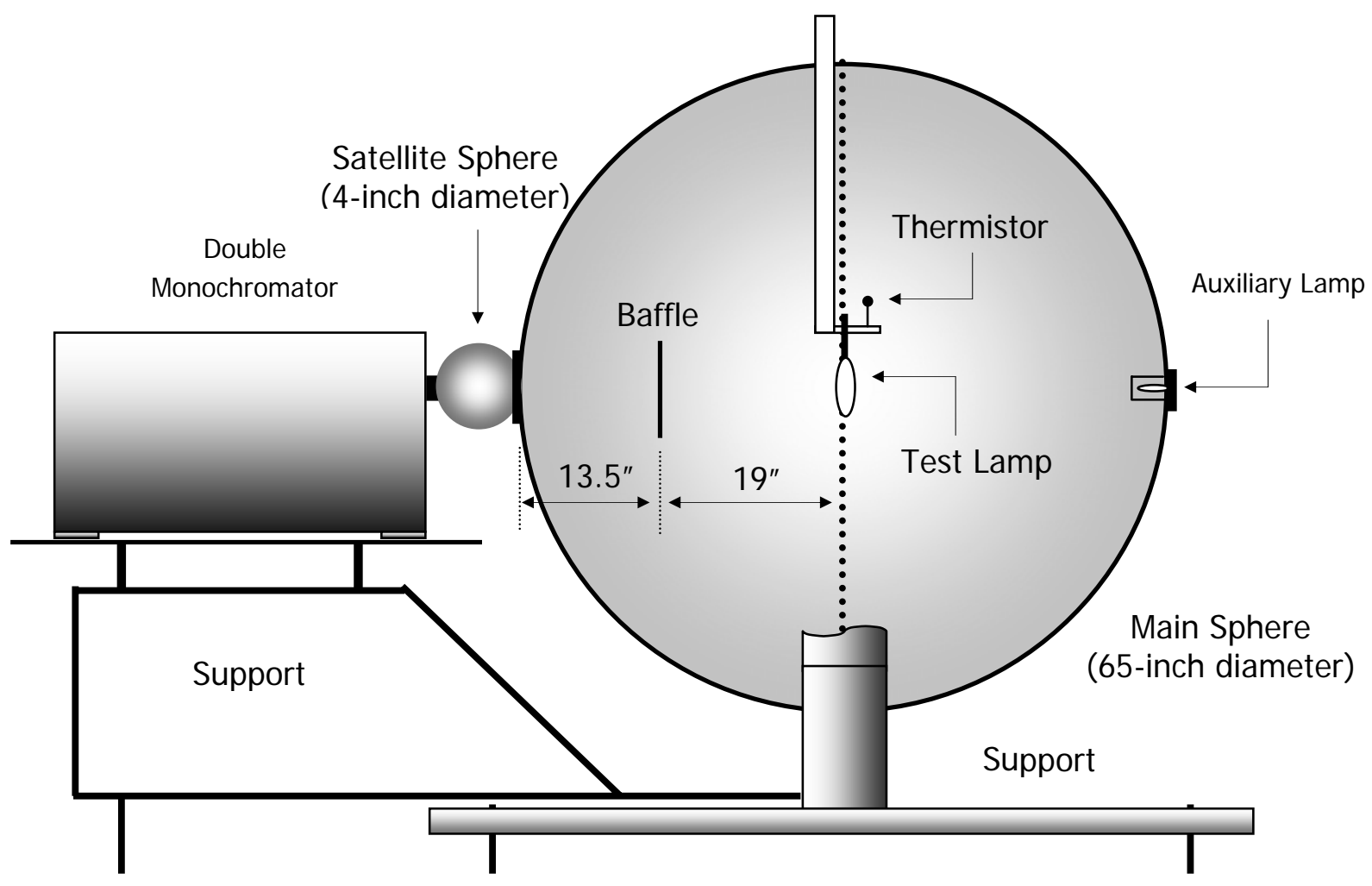

Figure 1. The integrating sphere system (ISS) 


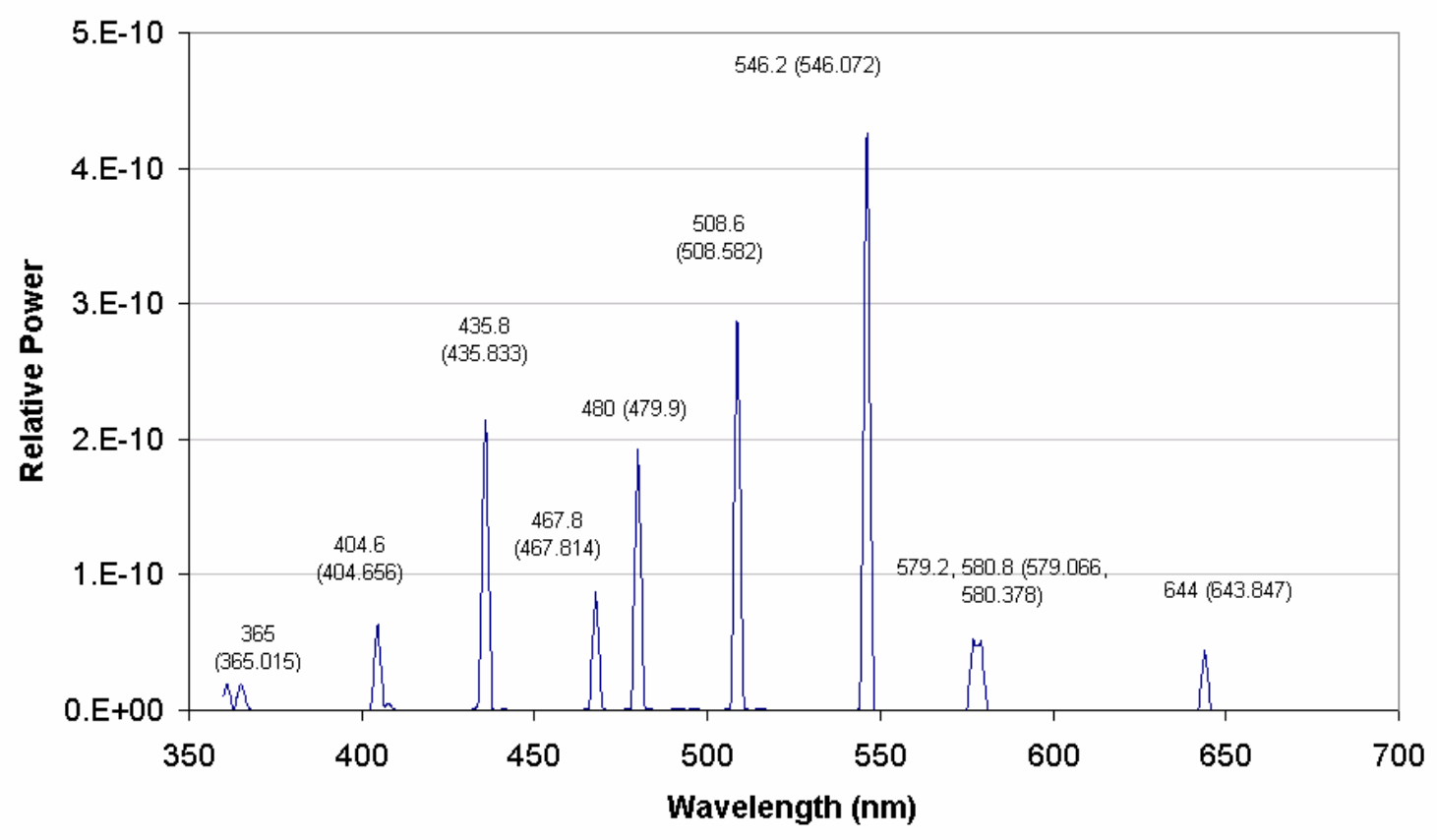

Figure 2. Measured line spectrum of the $\mathrm{HgCd} / 10$ spectral lamp. Values in parenthesis are the reference values for corresponding peaks. 

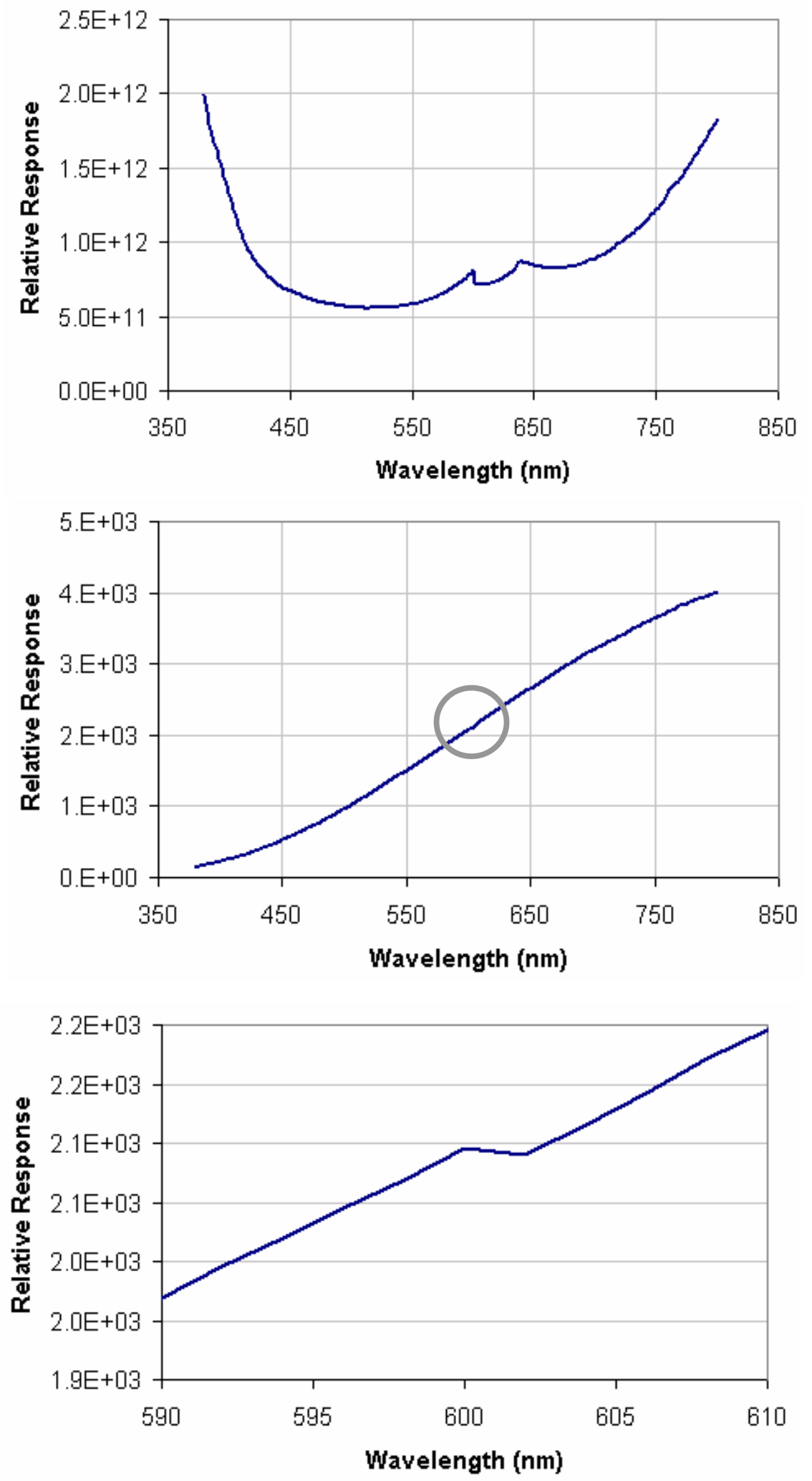

Figure 3. (a) Relative spectral response curve obtained by manual operation, (b) measured spectrum of the spectral standard (94406) inside the sphere using the calibration curve obtained by manual operation, and (c) enlarged portion showing the abnormal portion around $600 \mathrm{~nm}$ indicated by the circle in (b). 

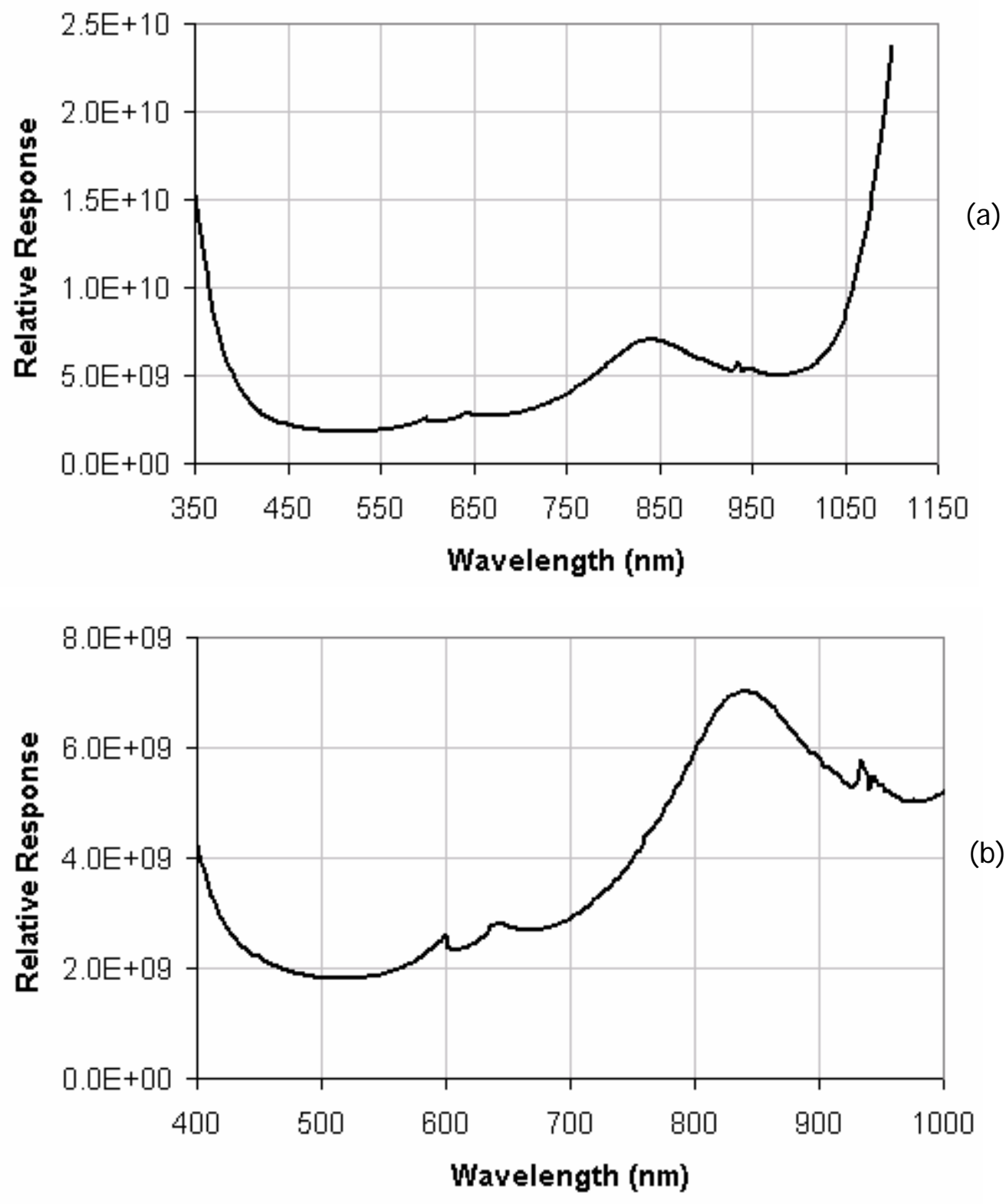

Figure 4. Relative spectral response of the ISS with the spectral standard located inside the sphere. (a) From 350 to $1100 \mathrm{~nm}$ measured at $2 \mathrm{~nm}$ intervals and (b) same data from 400 to $1000 \mathrm{~nm}$ at $2 \mathrm{~nm}$ intervals. 